\title{
Resilience and School Happiness Through Participation of High School Students in the School Sports Club
}

\author{
Hohyun Song ${ }^{1}$, Jihwan Song ${ }^{2}$ and Seungman Lee ${ }^{3}$ \\ ${ }^{1}$ Adjunct Professor, Korea National University of Education, 250 Taeseongtabyeon- \\ ro, Gangnae-myeon, Heungdeok-gu, Cheongju-si, Chungbuk, Republic of Korea \\ ${ }^{2}$ Professor, Jeonju University of Education, 50 West Hak-ro, Wansan-gu, Jeonju, \\ North Jeolla Province, Republic of Korea \\ ${ }^{3}$ Adjunct Professor, Kyunghee University, 1732 Dukyoung-ro, Giheung-gu, Yongin-si, \\ Republic of Korea \\ 1hohyunss@nate.com, ${ }^{2}$ ufosong114@jnue.kr, ${ }^{3}$ lsm14pe@gmail.com
}

\begin{abstract}
This study examined the effects of self-esteem on resilience and school happiness of high school students participating in school sports clubs. We aimed to provide primary data on the role of school sports clubs in the promotion of school happiness and how they can be used for this purpose. Through convenience sampling, this research selected around 324 Korean high school students (84 for a preliminary and 240 for a primary survey) participating in school sports clubs. For data analyses, we used frequency, reliability and validity tests, descriptive statistics, correlation analysis, and multiple regression analysis. Results were: First, there was a significant correlation between self-esteem, resilience, and school happiness; second, positive self-esteem had positive effects on all subfactors of resilience, and negative selfesteem had negative effects on these same subfactors; third, positive self-esteem had positive effects on all subfactors of school happiness, and negative self-esteem had negative effects on some subfactors (student-teacher relationship, environmental satisfaction, learning activity pleasure, and psychological stability). Therefore, the development of ways to expand school sports clubs may help to enhance high school students' self-esteem and resilience, so that students, who spend most of their time in school, can feel happy in this daily recurring setting.
\end{abstract}

Keywords: High school students, School sports clubs, Self-esteem, Resilience, School happiness

\section{Introduction}

The youth of a nation is its future. To predict the future of a country, its educational level and happiness index are crucial indicators. In that sense, youth happiness is essential, but the results of the recent Korean Youth Happiness Index, reported through various broadcasting and Internet media, is of concern: According to the survey by the Yonsei University Institute for Social Development in 2017, the Korean Youth Happiness Index ranked 20th (88 points) among the OECD members. Somewhat contrastingly, a survey conducted in 2016 by the Save the Children, an international aid organization, showed that Korea reached an advanced

Article Info:

Received (January 12, 2020), Review Result (February 27, 2020), Accepted (April 3, 2020) 
economic and educational level among the OECD countries, ranking the 1st in tertiary education, 11th in national competitiveness, and 13th in per capita gross national income. Notwithstanding, the Korean youth suicide rate is the world's number one, three times higher than the average rate for youth among the OECD countries, and suicide has been the number one leading cause of death among adolescents for the last ten years. Physical activities, such as sports, have recently received much attention because they help promote school happiness, and the Korean government has introduced and implemented sports club programs in schools [1]. According to several studies on the effectiveness of school sports clubs, about $67 \%$ of adults who felt happy in high school were more interested in sports activities and feel much happier in adulthood than those who had high academic achievement (3.5\%; [2]). Such findings indicate that their school experiences affect their happiness during adulthood. This study aimed to provide primary data on the role of school sports clubs in the promotion of school happiness and how they can be used for this purpose. Further, it aimed to help develop research and education programs for high school students. With these intents, we produced three research hypotheses, as follows: (1) Hypothesis 1: the self-esteem of high school students participating in school sports clubs would have a positive effect on resilience. (2) Hypothesis 2: their self-esteem would have a positive effect on school happiness. (3) Hypothesis 3: their resilience would have a positive effect on school happiness.

\section{Sample}

We used convenience sampling for sample recruitment. The preliminary survey occurred in May 2019, and 84 students in the South and North Jeolla Province participated; the primary survey occurred in October 2019, and 240 students in Gwangju Metropolitan City participated. The general characteristics of the samples are shown in [Table 1].

Table 1. Descriptive statistics analysis

\begin{tabular}{|c|c|c|c|c|c|}
\hline \multirow{3}{*}{ Characteristics } & \multirow{2}{*}{ Group } & \multicolumn{2}{|c|}{ Preliminary survey } & \multicolumn{2}{c|}{ Primary survey } \\
\cline { 3 - 6 } & & Frequency (n) & $\begin{array}{c}\text { Composition rate } \\
(\%)\end{array}$ & Frequency (n) & $\begin{array}{c}\text { Composition rate } \\
(\%)\end{array}$ \\
\hline \multirow{3}{*}{ Gender } & Male & 44 & 52.4 & 103 & 42.9 \\
\cline { 2 - 6 } & Female & 40 & 47.6 & 137 & 57.1 \\
\hline \multirow{3}{*}{ Grade } & 1 & 34 & 40.5 & 87 & 36.3 \\
\cline { 2 - 6 } & 2 & 29 & 34.5 & 99 & 41.3 \\
\cline { 2 - 6 } & 3 & 21 & 25 & 54 & 22.5 \\
\hline \multicolumn{2}{|r|}{ Total } & 84 & 100 & 240 & 100 \\
\hline
\end{tabular}

\section{Instruments}

Questionnaires were used as survey tools. The questionnaires used in this research were selected based on their reliability and validity values, as they had already been proven in several previous researches. Questions on the general characteristics of the sample consisted of gender and grade. To measure participants' self-esteem, we used the translated version of the 10-item Rosenberg Self-Esteem Scale (RSES) by [3], developed by [4]. It has two subscales: positive (5 items) and negative self-esteem (5 items). To measure participants' resilience, we used the 27-item questionnaire developed by [5] and used by [6]. It consists of three subscales: control ( 9 items), positivity (9 items), and sociality ( 9 items). To measure 
participants' school happiness, we used the 22-item Authentic Happiness Inventory Questionnaire suggested by [7], which was developed considering school situations by [8]. It has 6 subscales: friendship, student-teacher relationship, self-efficacy, environmental satisfaction, learning activity pleasure, and psychological stability. Reliability refers to the degree of consistency of questions present in a measure, covering such concepts as response stability, consistency, and predictability [9]. There are several ways to measure reliability, but this study used the Cronbach's $\alpha$ coefficient. The Cronbach's $\alpha$ coefficient of the self-esteem measure ranged from .776-.893, that for the resilience measured range from .866-.894, and for the school happiness measure ranged from .441-.883. All subfactors of all measures showed Cronbach's $\alpha$ coefficients of .6 or higher, which exceeded the required threshold; nevertheless, friendship, one of the subfactors of the school happiness measure, showed a value of .441 , so it was excluded from this research.

\section{Data processing}

The collected data were analyzed using SPSS 18.0 and AMOS 18.0. First, frequency analyses were conducted to examine the demographic characteristics of the samples. Second, Cronbach's $\alpha$ coefficients were calculated to verify the reliability of the measures. Third, a confirmatory factor analysis was conducted to verify the validity of the measurement tools. Fourth, descriptive statistics were calculated to describe and summarize the features of selfesteem, resilience, and school happiness. Fifth, correlation analysis was performed to analyze the correlation between the variables. Sixth, multiple regression analysis was conducted to analyze the effects of subjects' self-esteem on resilience and school happiness.

\section{Results}

As for descriptive statistics (mean, standard deviation, skewness, kurtosis), we analyzed the total scores of self-esteem, resilience and school happiness, and of all their subfactors, as shown in [Table 2]. The means ranged from 2.49 to 4.18 , and the standard deviation ranged from .61 to .95 . Next, the absolute value of skewness was distributed from .01 to .65 , and the absolute value of kurtosis was distributed from .06 to .58. Previous studies have shown that, for univariate normality tests to prove the normal distribution of the variables, skewness values should be $< \pm 3.0$ [10], and kurtosis values should be $< \pm 10.0$ [11]. Our results showed that all variables met these criteria, so they proved their normal distribution.

Table 2. Descriptive statistics analysis

\begin{tabular}{|c|c|c|c|c|c|}
\hline \multicolumn{2}{|c|}{ Variables } & Mean & $\begin{array}{c}\text { Standard } \\
\text { Deviation }\end{array}$ & Skewness & Kurtosis \\
\hline \multirow{3}{*}{ Self-esteem } & Positive Self esteem & 4.18 & .712 & -.65 & .09 \\
\cline { 2 - 6 } & Negative Self esteem & 2.49 & .792 & .46 & .06 \\
\hline \multirow{4}{*}{ Resilience } & Sociality & 3.81 & .672 & .26 & -.52 \\
\cline { 2 - 6 } & Positivity & 3.96 & .666 & -.17 & -.58 \\
\cline { 2 - 6 } & Control & 4.01 & .612 & -.09 & -.48 \\
\hline \multirow{3}{*}{\begin{tabular}{c} 
School \\
\cline { 2 - 6 }
\end{tabular}} & Student-Teacher relationship & 3.73 & .897 & -142 & -.20 \\
\cline { 2 - 6 } & Self-efficacy & 3.65 & .845 & .01 & -.49 \\
\cline { 2 - 6 } & Environmental satisfaction & 3.64 & .896 & -.13 & -.53 \\
\cline { 2 - 6 } & Learning activity pleasure & 3.61 & .954 & -.28 & -.42 \\
\hline
\end{tabular}




\begin{tabular}{|l|l|l|l|l|l|}
\hline & Psychological stability & 2.90 & .933 & .32 & -.26 \\
\hline
\end{tabular}

Next, Results of multiple regression analysis on the influence of self-esteem on resilience in our sample are shown in [Table 3].

Table 3. Influence of self-esteem on resilience

\begin{tabular}{|c|c|c|c|c|c|c|}
\hline $\begin{array}{l}\text { Dependent } \\
\text { Variables }\end{array}$ & $\begin{array}{c}\text { Independent } \\
\text { Variables }\end{array}$ & S.E. & $\beta$ & $\mathrm{t}$ & $\mathrm{p}$ & $\begin{array}{c}\text { Tolerance } \\
\text { limits }\end{array}$ \\
\hline \multirow{4}{*}{ Control } & Constant & .348 & - & 6.640 & $.000 * *$ & - \\
\hline & Positive Self esteem & .063 & .482 & 7.232 & $.000 * *$ & .511 \\
\hline & $\begin{array}{l}\text { Negative Self } \\
\text { esteem }\end{array}$ & .049 & -.250 & -3.745 & $.000 * *$ & .511 \\
\hline & \multicolumn{6}{|c|}{$\mathrm{R}(\mathrm{a})=.680 \mathrm{R}^{2}=.463$ adj $\mathrm{R}^{2}=.458 \mathrm{~F}=102.029 \mathrm{p}=.000$ Durbin-Watson $=1.830$} \\
\hline \multirow{4}{*}{ Positivity } & Constant & .307 & - & 7.260 & $.000 * *$ & - \\
\hline & Positive Self esteem & .055 & .551 & 9.306 & $.000 * *$ & .511 \\
\hline & $\begin{array}{l}\text { Negative Self } \\
\text { esteem }\end{array}$ & .043 & -.263 & -4.436 & $.000 * *$ & .511 \\
\hline & \multicolumn{6}{|c|}{$\mathrm{R}(\mathrm{a})=.759 \mathrm{R}^{2}=.575$ adj $\mathrm{R}^{2}=.572 \mathrm{~F}=160.597 \mathrm{p}=.000$ Durbin-Watson $=2.191$} \\
\hline \multirow{4}{*}{ Sociality } & Constant & .314 & & 6.755 & $.000 * *$ & - \\
\hline & Positive Self esteem & .057 & .582 & 8.806 & $.000 * *$ & .511 \\
\hline & $\begin{array}{l}\text { Negative Self } \\
\text { esteem }\end{array}$ & .044 & -.139 & -2.095 & $.037 *$ & .511 \\
\hline & \multicolumn{6}{|c|}{$\mathrm{R}(\mathrm{a})=.686 \mathrm{R}^{2}=.471$ adj $\mathrm{R}^{2}=.466 \mathrm{~F}=105.489 \mathrm{p}=.000$ Durbin-Watson $=1.918$} \\
\hline
\end{tabular}

Results showed that all subfactors of self-esteem affected those of resilience: First, positive self-esteem had a statistically significant positive effect on control $(\beta=.482, p<.001)$, while negative self-esteem had a statistically negative effect on control $(\beta=-.250, \mathrm{p}<.001)$, and selfesteem showed an R2 value of .463 when predicting control. Furthermore, positive selfesteem had a statistically significant positive effect on positivity $(\beta=.551, p<.001)$, while negative self-esteem had a statistically significant negative effect on positivity $(\beta=-.263$, $\mathrm{p}<.001$ ), and self-esteem indicated an R2 value of .575 when predicting positivity. Finally, positive self-esteem had a statistically significant positive effect on sociality $(\beta=.582, p<.001)$, while negative self-esteem had a statistically significant negative effect on sociality ( $\beta=-.139$, $\mathrm{p}<.05)$, and self-esteem showed an R2 value of .471 when predicting sociality.

The results of multiple regression analysis to examine the influences of self-esteem on school happiness in our sample are shown in [Table 4].

Table 4. Influence of self-esteem on school happiness

\begin{tabular}{|c|c|c|c|c|c|c|}
\hline $\begin{array}{c}\text { Dependent } \\
\text { Variables }\end{array}$ & $\begin{array}{c}\text { Independent } \\
\text { Variables }\end{array}$ & S.E. & $\beta$ & $\mathrm{t}$ & $\mathrm{p}$ & $\begin{array}{c}\text { Tolerance } \\
\text { limits }\end{array}$ \\
\hline
\end{tabular}




\begin{tabular}{|c|c|c|c|c|c|c|}
\hline \multirow{4}{*}{$\begin{array}{l}\text { Student } \\
\text { Teacher } \\
\text { relationship }\end{array}$} & Constant & .494 & & 2.923 & $.004 * *$ & \\
\hline & Positive Self esteem & .089 & .502 & 7.082 & $.000 * *$ & .511 \\
\hline & Negative Self esteem & .070 & -.163 & -2.299 & $.022 * *$ & .511 \\
\hline & \multicolumn{6}{|c|}{$\mathrm{R}=.627 \mathrm{R}^{2}=.393$ adj $\mathrm{R}^{2}=.387 \mathrm{~F}=76.578 \mathrm{p}=.000$ Durbin-Watson=1.759 } \\
\hline \multirow{4}{*}{ Self-efficacy } & Constant & .457 & & 2.713 & $.007 * *$ & \\
\hline & Positive Self esteem & .083 & .542 & 7.797 & $.000 * *$ & .511 \\
\hline & Negative Self esteem & .065 & -.136 & -1.954 & .052 & .511 \\
\hline & \multicolumn{6}{|c|}{$\mathrm{R}=.644 \mathrm{R}^{2}=.415 \operatorname{adj} \mathrm{R}^{2}=.410 \mathrm{~F}=84.128 \mathrm{p}=.000$ Durbin-Watson $=1.874$} \\
\hline \multirow{4}{*}{$\begin{array}{c}\text { Environmental } \\
\text { satisfaction }\end{array}$} & Constant & .476 & & 2.562 & $.011^{*}$ & \\
\hline & Positive Self esteem & .086 & .530 & 7.756 & $.000 * *$ & .511 \\
\hline & Negative Self esteem & .067 & -.170 & -2.495 & $.013^{*}$ & .511 \\
\hline & \multicolumn{6}{|c|}{$\mathrm{R}=.660 \mathrm{R}^{2}=.436$ adj $\mathrm{R}^{2}=.431 \mathrm{~F}=91.507 \mathrm{p}=.000$ Durbin-Watson=1.707 } \\
\hline \multirow{4}{*}{$\begin{array}{l}\text { Learning } \\
\text { activity } \\
\text { pleasure }\end{array}$} & Constant & .518 & & 2.942 & $.004 * *$ & \\
\hline & Positive Self Esteem & .094 & .464 & 6.639 & $.000 * *$ & .511 \\
\hline & Negative Self-esteem & .073 & -.224 & -3.201 & $.002 * *$ & .511 \\
\hline & \multicolumn{6}{|c|}{$\mathrm{R}=.640 \mathrm{R}^{2}=.410$ adj $\mathrm{R}^{2}=.405 \mathrm{~F}=82.289 \mathrm{p}=.000$ Durbin-Watson=1.984 } \\
\hline \multirow{4}{*}{$\begin{array}{l}\text { Psychological } \\
\text { stability }\end{array}$} & Constant & .600 & & 4.294 & $.000 * *$ & \\
\hline & Positive Self Esteem & .108 & .221 & 3.030 & $.003 * *$ & .511 \\
\hline & Negative Self-esteem & .085 & -.422 & -5.793 & $.000 * *$ & .511 \\
\hline & \multicolumn{6}{|c|}{$\mathrm{R}=.598 \mathrm{R}^{2}=.357$ adj $\mathrm{R}^{2}=.352 \mathrm{~F}=65.891 \mathrm{p}=.000$ Durbin-Watson=1.969 } \\
\hline
\end{tabular}

First, positive self-esteem had a statistically significant positive effect on student-teacher relationship $(\beta=.502, \mathrm{p}<.001)$, while negative self-esteem had a statistically significant negative effect on student-teacher relationship $(\beta=-.163, \mathrm{p}<.05)$, and self-esteem showed an R2 value of .393 when predicting student-teacher relationship. Next, positive self-esteem had a statistically significant positive effect on self-efficacy $(\beta=.542, \mathrm{p}<.001)$, while negative selfesteem did not have any significant effect on self-efficacy $(\beta=-.136, p>.05)$, and self-esteem showed an R2 value of .415 when predicting self-efficacy. Further, positive self-esteem had a statistically significant positive effect on environmental satisfaction $(\beta=.530, p<.001)$, while negative self-esteem had a statistically significant positive effect on environmental satisfaction $(\beta=-.170, p<.05)$, and self-esteem indicated an R2 value of .436 when predicting environmental satisfaction. Additionally, positive self-esteem had a statistically significant positive effect on learning activity pleasure $(\beta=.464, \mathrm{p}<.001)$, while negative self-esteem had a statistically significant negative effect on learning activity pleasure $(\beta=-.224, p<.01)$, and self-esteem showed an R2 value of .410 when predicting learning activity pleasure. Finally, positive self-esteem had a statistically significant positive effect on psychological stability $(\beta=.221, \mathrm{p}<.01)$, while negative self-esteem showed a statistically significant negative effect on psychological stability $(\beta=-.422, p<.001)$, and self-esteem showed an $\mathrm{R} 2$ value of .357 when predicting psychological stability. 


\section{Conclusion and suggestions}

This research analyzed the effects of self-esteem on resilience and school happiness among high school students participating in school sports clubs, and provided basic data on the role of school sports clubs in the promotion of school happiness and how they can be used for this purpose. We performed this study with the intent to help develop research and education programs that improve students' school happiness. For this purpose, this research targeted 324 high school students who participated in school sports clubs. In our sample, there was a significant positive correlation between positive self-esteem and all subfactors of resilience and school happiness, and negative self-esteem had a negative correlation with all other variables. Moreover, positive self-esteem had a positive influence on all subfactors of resilience (control, positivity, and sociality), and negative self-esteem had a negative influence on all subfactors of resilience. Additionally, positive self-esteem positively affected all subfactors of school happiness (student-teacher relationship, self-efficacy, environmental satisfaction, learning activity pleasure, and psychological stability), while negative selfesteem negatively affected some subfactors of school happiness (student-teacher relationship, environmental satisfaction, learning activity pleasure, and psychological stability). Finally, regarding the resilience subscales and their influence on school happiness, control had a positive influence on all its subfactors, except for friendship; positivity had a positive effect on all subfactors and sociality had a positive effect on friendship and self-efficacy.

This study also had many limitations. First, since the samples were composed of high school students living in some specific areas of Korea, our collected data was partially biased owing to sample- and region-related tendencies; future studies should expand the geographical scope of their samples and select more diverse participants, so that the findings can be further generalized. We also suggest taking into account various age groups and personal characteristics. Second, regarding research outcomes, there are limitations in presenting empirical data on whether or not school sports clubs indeed contribute to building self-esteem and resilience; therefore, to help with the expansion and diversification of school sports clubs, we think future studies should analyze their influence through comparative and analytical designs after dividing the sample into participants and non-participants of these clubs [12][13][14].

\section{References}

[1] J. S. Moon and G. J. Choi, "The effects of physical self-concept and social skills of middle school students participating in school sports club on school happiness," The Korean Journal of Sport, vol.15, no.3, pp.119128, (2017)

[2] Ministry of Education, "Plans to promote school sports in 2016," Ministry of Education, Sejong, (2016)

[3] B. J. Jun, "Self-Esteem: A test of it's Measurability," collection of writings Yonsei, vol.11, pp.107-129, (1974)

[4] M. Rosenberg, "Society and the adolescent self-image," Princeton University Press, NJ, (1965)

[5] R. L. Duran, "Communicative adaptability: A measure of social communicative competence," Communication Quarterly, vol.31, pp.320-326, (1983)

[6] W. Y. Shin, M. G. Kim, and J. H. Kim, "Developing measures of resilience for Korean adolescents and testing cross, convergent, and discriminant validity," Korean Journal of Youth Studies, vol.20, no.4, pp.105131, (2009)

[7] M. P. Seligman, "Authentic happiness: Using the positive psychology to realize your potential for lasting fulfillment," Free Press, New York, (2002)

[8] J. B. Kim, and T. E. Kim, "The development and validation of Korean school happiness scale," The Korean Journal of Education Psychology, vol.22, no.1, pp.259-279, (2008) 
[9] C. H. Cho, "Application of SPS/AMOS: Statistic analysis of structural equation model," Chungram Press, Seoul, (2016)

[10] S. G. West, J. F. Finch, and P. J. Curran, "Structural equation model with non-normal variables: Problems and remedies. In R. Hoyle (Ed.), Structural Equation Modeling: Concepts, Issues and Applications," Newbury Park, CA: Sage, (1995)

[11] R. B. Kline, "Principles and practice of structural equation modeling (3nd ed.)," New York: Guilford, (2011)

[12] Y. H. Kwon, J. I. Park, and H. M. Kim. "The effects of stress and life satisfaction on smartphone addiction in college students," International Journal on Consulting Psychology for Patients, vol.3. no.1. pp.1-6, (2019)

[13] H. G. An and C. M. Yoon, "The influential factors on the fever management of mothers with their first child in infancy," International Journal of Child Welfare Promotion and Management, vol.3, no.1, pp.1-6, (2019)

[14] S. O. Kim "The relationship between cognitive function of the elderly and oral health and activities of daily living.” International Journal of Elderly Welfare Promotion and Management, vol.3, no.1, pp.1-6, (2019) 
Effects of Self-Esteem on Resilience and School Happiness of Korean High School Students Participating in School Sports Clubs

This page is empty by intention.

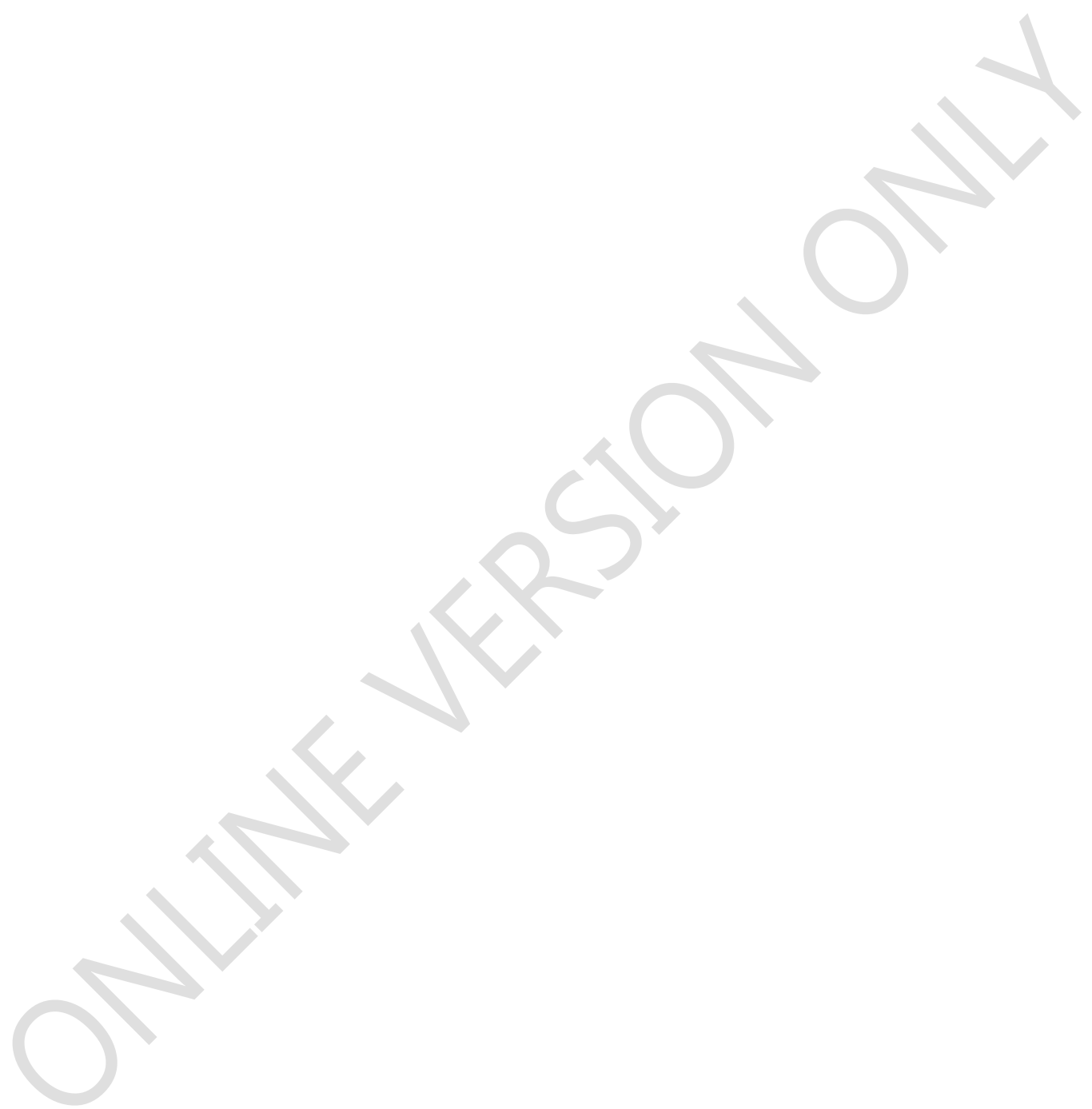

